\title{
Attracting Foreign Direct Investment
}

\author{
The Chilean Government's Role Promoting Renewable Energy \\ Kyle S. Herman \\ Rutgers University, Division of Global Affairs \\ Newark, New Jersey, USA \\ kyle@creee.org, ksherman2@usfca.edu
}

\begin{abstract}
The development and implementation of renewable energy power plants is important for Chile in order to increase energy security, supply remote mines with electricity, and eventually decrease energy costs. The Chilean government has promoted renewable energy and attracted Foreign Direct Investment FDI) to develop largescale renewable energy projects. However, the policies cannot sufficiently attract FDI in unproven renewable energies such as Concentrated Solar Power, though it is proven elsewhere. This paper examines the Chilean government's renewable energy policies and investigates potential pitfalls of early to mid-stage capital for the renewable energy industry. Recommendations include linking the mining industry to the large-scale renewable energy industry in order to drive innovation and investment. A renewable energy technopole, or innovation center, should be established to link academia with private enterprise and government policy. Data for this research was acquired through in-person interviews with officials from CORFO (Economic Development Agency) and CER (Center for Renewable Energy) in Santiago, Chile, in June 2012.
\end{abstract}

Keywords- FDI; Chile; government policy; renewable energy investment; valley of death; early-stage financing; capital investment; Center for Renewable Energy; CORFO; renewable mining; technopole; energy innovation.

\section{INTRODUCTION}

Without substantial liquidity in Chile's domestic banking sector, Foreign Direct Investment (FDI) has played a significant role in developing its infrastructure. This is no less evident than in the energy sector, which has received $\$ 13$ billion FDI in the period from 1990-2008 (from 2008-2012, the sector garnered $43 \%$ of total country investments). However, much of this FDI is directed towards proven energy technologies, and sometimes fails to drive innovation in the renewable energy sector. Innovation in the renewable energy sector can only occur with a concerted triangulation between seed capital, government policy, and a skilled workers. In short, the Chilean government does well to attract FDI in the energy industry, but there remain some pivotal gaps to fill before the country can scale up renewable energy.

\section{RENEWABLE ENERGY IN CHILE}

Chile was among the first countries in the world to privatize electricity, which began on the utility scale in 1982 [1]. As a developing nation at the time, this was an audacious and provocative government policy decision. After being trained at the University of Chicago, Chilean graduates returned to Chile to embark on a systematic restructuring of government economic policy. This marked the beginning of Chilean government efforts to liberalize the Chilean economy in general, and began the slow transition to opening up Chile to Renewable Energy (Non-Conventional Renewable EnergyNCRE).

\section{A. Electricity Overview}

A small Latin American country with a population of around seventeen million people, Chile has strong commitments to climate change mitigation. This has created a palatable market for foreign investors. It ratified the UN Framework Convention on climate change and the Kyoto Protocol. In 2009 the president created an Inter-Ministerial Committee on climate change. Finally, in 2012, the government released its National Energy Strategy linking energy security with climate change [2]. There has been a tacit understanding of energy supply risks due to its heavy dependence on imported energy, (75\% of fuels are imported), and the government has thus pushed forward renewable energy and energy efficiency legislation [3]. Lastly, Chile was a pioneer in employing renewable energy for industrial uses; in 1972 it installed a solar plant in the city of Antofagasta [4].

\section{B. Key Aspects of Electricity Generation in Chile}

- $\quad 37 \%$ of the countries' electricity is consumed by the mining sector [5].

- Industrial sector consumes 31\% [6].

- Commercial and public sectors consume 14\% [7].

- The rates for the use of the transmission system are set every four years by the Study of the trunk transmission [8].

- Power plants smaller than $9 \mathrm{MW}$ have the right to a price stabilization mechanism.

The domestic energy market is divided into four main sectors. The two Northern sectors, SIC (Central Interconnected System) and SING (Northern Interconnected System), are the most important because these make up nearly $16,000 \mathrm{MW}$ 
combined. SING is powered almost exclusively by fossil fuel and, interestingly, is supplies nearly $90 \%$ of its electricity to mining and heavy industry (a point discussed later in this paper). SIC fires $51 \%$ of its energy through fossil fuel with the remaining created by large hydro (47\%), wind energy $(2 \%)$, and biomass (2\%). Meanwhile the two Southern systems, the Aysen System (SEA) and the Magallanes System (SEM), only account for about $150 \mathrm{MW}$ combined, most of which is natural gas, diesel, or large hydro. This article deals specifically with SIC and SING large-scale utility energy.

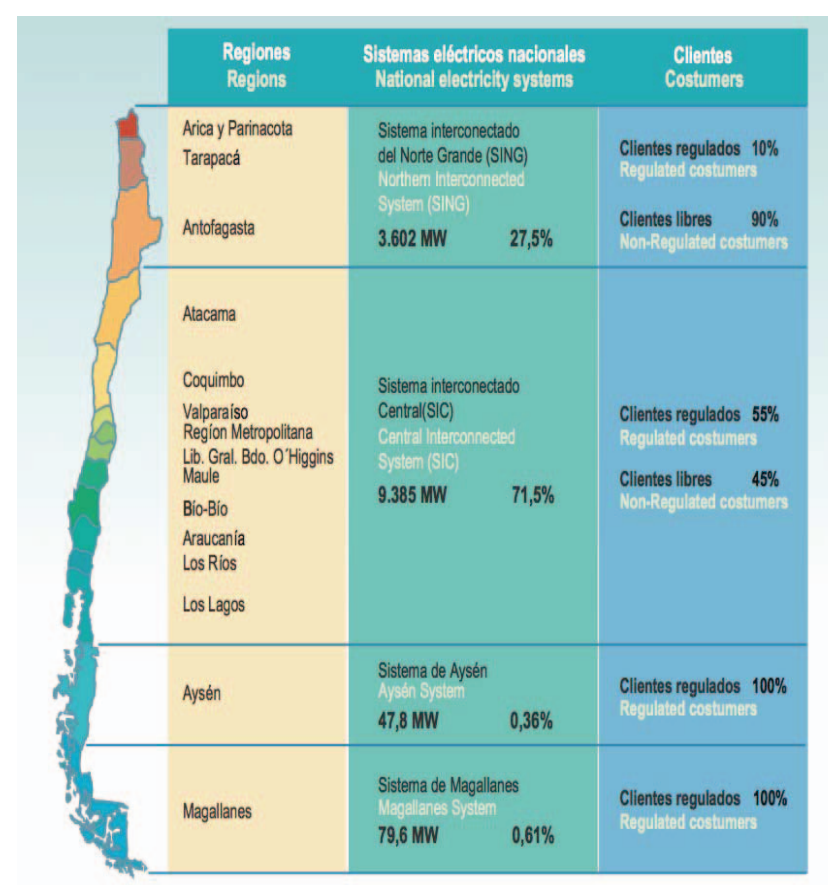

Fig. 1. The four electricity sectors in Chile.

\section{NON-CONVENTIONAL RENEWABLE ENERGY (NCRE) LEGISLATION AND THE SPOT MARKET}

Several pieces of legislation guide NCRE in Chile. Many of these laws recently entered into effect. For a country in South America, the Chilean RE policy can be considered quite progressive. In comparison to European countries, however, the legislation falls short and does not have the effect of attracting certain kinds of investment. Specifically, the NCRE legislation fails to attract enough seed capital or early to midstage financing (a common occurrence in developing countries). The key policies and government mandates for renewable energy are briefly outlined below:

\section{- $\quad$ Law 19,940, March 2004}

Modifies aspects of the electricity market affecting all generators by introducing elements especially applicable to NCRE [9].

- $\quad$ Law 20,257, April 2008

This law established a Renewable Energy Portfolio Standard and requires generators to source $5 \%$ of their electricity from renewable energy (non-conventional). The percentage will increase to $10 \%$ by 2024 . Non-compliant companies are obliged to pay a penalty [10].

- $\quad$ Law 20,365, August 2010

Creates a tax benefit that incentivizes the investment in solar thermal collectors for new constructions.

- $\quad$ Law 19.940 (The Short Law)

This law establishes nodal prices to construct a contract market among unregulated customers [11].

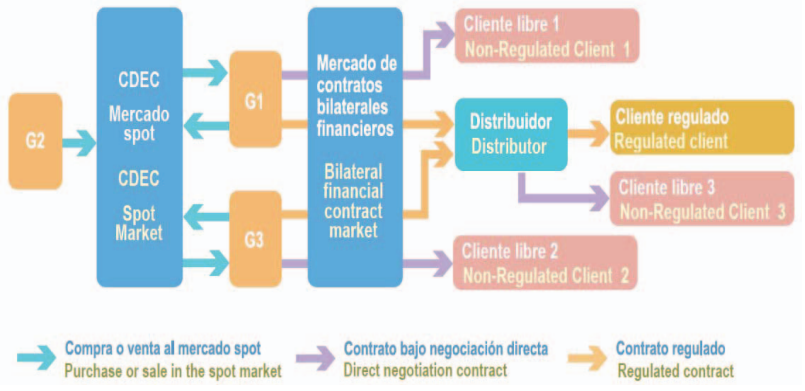

Fig. 2. The theoretical operation of the Spot Market in Chile

- $\quad$ Supreme Decree No. 244

Suppliers with a capacity of less than 9MW are exempted from payments for use of the main transmission lines [12].

- Decree Law 600, The Statute on Foreign Investment

Since 1974, this law regulated the entry of foreign capital as foreign direct investment, using stable, transparent and simple rules. It applies to individuals or legal entities or Chileans who reside abroad and invest in Chile [13].

\section{A. Government Agencies Responsible for NCRE}

Several different government agencies support the wide scale development of NCRE in Chile. These include CORFO (Economic Development Agency), CER (Center for Renewable Energy), CNE (National Energy Commission) and AchEE (Chilean Energy Efficiency Agency). CORFO is involved mostly in finance activities and fostering innovation. The CER is focused specifically on renewable energy and provides resources for developers and investors to ascertain available instruments (though the agency is still in its infancy stages). The CNE sets and monitors electricity prices, based on nodal price ("spot market"), updated every six months [14]. Finally the AchEE focuses specifically on energy efficiency. 2 This paper is predominantly concerned with CER and CORFO, because these agencies deal with seed capital and the direct promotion of renewable energy investments. Eventually the CER will be responsible for supplying all relevant NCRE data, alleviating the burden on investors to acquire expensive data through other means. Below are two examples of data supplied by CER.

\section{B. Corfo: The Chilean Economic Development Organization}

The task of Corfo is to assist business development in Chile. It accomplishes this by helping entrepreneurial and innovative companies become marketable in Chile, assisting 
with entrance into the commercial market by opening up specific windows of opportunity.

Some significant projects Corfo has aided since 2005 are:

- Credit lines to commercial banks for on-lending to RE projects. These include a thirty month grace period and repayment up to 12 years with a maximum of \$513 million to individual projects.

- Project Preparation matching funds for early stage development activities including resource assessment, feasibility and environmental studies, and Clean Development Mechanism (CDM) documentation.

- Cost-sharing up to 5 percent of estimated investment.

- Over 100 such projects have been supported.

- Loans are guaranteed up to 50\% pari-passu, with a maximum terms of 12 years, and the guarantee fee is $1 \%$ per year

\section{Investment in Non-Conventional Renewable Energy}

- Total FDI investment in Chilean Energy system from 1990-2008 was \$13,182 million (representing 20\% of all FDI over that period) [15].

- Total investment in energy sector 2008-2012 estimated to be $\$ 24,459$ million (equaling about $43 \%$ of total country investments) [16].

- Subsidies for preliminary studies for NCRE: Programs are eligible under the Clean Development Mechanism (Kyoto Protocol), with investments over \$400,000 [17].

- Program for basic engineering studies: This subsidy covers up to $50 \%$ of engineering, electrical connection, or environmental impact studies up to $\$ 160,000$ [18].

- Open tenders where the generators who participate could be awarded a State subsidy to improve the energy grid [19].

\section{Subordinated Debt Financing}

A problem in the NCRE investment market cited by both the Chilean Government [20] and private analysts is the domestic finance sector's lack of knowledge of differing clean energy technologies. The general lack of knowledge, or knowledge-capital, results in a sluggish investment environment for NCRE; ultimately this leads to higher interest rates, extra required guarantees, and an overall shortage of funding alternatives [21]. The Chilean Government should encourage the use of use of subordinated debt financing in large-scale NCRE projects because this would allow for a "reduction of the amount of equity required and therefore avoid the additional costs of equity" [22]. As opposed to senior debt, subordinated debt can better bridge knowledge gaps by scaling up at a faster rate.

\section{Discussion: The Valley of Death oR Chilecon VALLEY?}

The Chilean Renewable Energy industry has great potential to become a silicon valley for RE technology. By following the lead of Silicon Valley, which has unprecedented success conjoining university, government, and private capital to drive innovative industries, Santiago could be one day considered Chilecon Valley. Yet two crucial impediments exist (or three if government policy is considered inadequate). The first is knowledge capital, and the second is early stage financing. Without early stage financing (venture capital, seed capital), the Valley of Death looms over Chilecon Valley.

\section{A. Pre-Commercialization}

"The Valley of Death" is a term that refers to new technologies unable to become marketable because they lack early stage financing, which is usually supplied by venture capitalists. The Valley of Death precludes innovative technologies from reaching development stages because projects cannot scale up and become marketable [23]. A project or company that falls into the Valley cannot be rescued without some other form of intervention in the market. Such projects have the characteristics of proven and demonstrable technology with low market demand. The perceived risk equates to an unmarketable early to mid-stage investment [24]. Innovative $\mathrm{RE}$ technologies, or even unproven technologies in a certain geographical area, may remain in the Valley of Death because investments are even too risky for venture capitalists.

The Chilean government can foster a Chilecon value by understanding its endogenous energy resources, such as Concentrated Solar Power and molten salt storage, and connecting its Universities to private enterprises exploring these specific renewable energies. It must be noted that the government has made strides in creating this type of environment, but it appears the policies are too broad and seek to incorporate too many technologies. The government cannot attempt to integrate all renewable energies into its knowledgecapital because this will create an abundance of moderately skilled workers (rather than experts), and will not lead to an innovative culture based around several very specific technologies. The government must make it a priority to incentivize innovation to allow focused learning in the renewable energy technology [26].

\section{B. The Valley of Death and Spot Prices}

Employing "spot" prices, which cannot distinguish between conventional energies and renewable energies, exacerbates the Valley of Death in Chile. Early stage financing is mostly unavailable for not yet tested renewable energy plants (though they may be proven in other countries). This causes investors to sink money into conventional energies instead. Therefore proven, conventional energies are more attractive. This "technological neutrality" favors conventional energy and will not stimulate NCRE investment unless it is "reviewed periodically as the technology curve progresses [for NCRE]. The surcharge established is too low to act as an incentive to fulfill the quota" [27]. 
Although the CER offers assistance in large-scale projects near commercial development, it does not help burgeoning projects requiring early-stage financing (only .5\% of early stage financing is sourced publicly, worldwide). Similarly, the CER offers some help with the prospecting (initial project phases) but not to extent that would result in proper levels of confidence to an early-stage private investor. Corfo does this to some degree, but it appears incapable of attracting large amounts of seed capital in the absence of international loaners. The amount of seed capital Corfo can leverage is rather small, and follows the trend of only investing in proven NCRE.

Although CORFO provides renewable energy prospecting data (National Energy Strategy 2012-2030), it is not of sufficient quality for investors because it lacks "basic technical studies" which forces developers to "dedicate time and resources to carrying out their own individual studies" [28]. In other words, early-stage private investment must be used to pay for this technical data, which seed capitalists are not intent on paying for. It would be more prudent if the government provided adequate data. Clear data includes not only technical feasibility studies but also long-term access to the grid and public electricity demand forecasts.

\section{POLICY RECOMMENDATIONS TO ENCOURAGE LARGE- SCALE RE PROJECTS IN CHILE}

The government should consider economies of scale while developing programs and legislation to promote NCRE in the future. By taking a step back and assessing the great resources Chile does have, it becomes easier to distinguish the gaps in policy. Clearly, there are gaps between the mining industry and renewable energy. Furthermore, it becomes evident that the country is on the brink of many technological breakthroughs if it can only realize the potential for cross-sectoral integration. Several points should be considered here.

\section{A. Concentrated Solar Power (CSP)}

International lenders have already taken notice of the dual characteristics of high energy-intensity in Chile in connection with high solar irradiation. In Northern Chile, where most mines are in operation, the potential for CSP is highly promising. One of CSP's fundamental costs, storage using molten salt, could be subsidized by the government because this salt is abundant in Chile.

Yet there remains a lack of demand, which needs correcting through more policy, and thus a market failure exists here. The government could offer domestic CSP developers substantially reduced mining concession fees and drive innovation in this storage technology, which will certainly be critical for the development of renewable energy on the large scale. Similarly, the government should encourage specific research centers tasked with storage technology, funded specifically for developing renewable energy storage.

Mining requires flat demand, but around the clock energy. This is precisely the role CSP could fill for mining operations. Most customers in the SING area need 24-hour flat demand. Therefore this more flexible technology has a better chance of getting a power purchasing agreement with an off-taker. Presently the government only requires $5 \%$ of the energy transmitted in the SING region to derive from NCRE; however, this law should be changed to increase more rapidly. This change, in collaboration with offering subsidies and incentives for CSP, could lead to a rapid uptake of the technology by mining companies. CSP plants can be highly beneficial to remote areas where conventional energy supply disruptions eats into mining profits. One example offering evidence of this uptake is already evident. SunDeison signed an agreement with CAP (Chilean Mining Group) for the construction of a 100MW photovoltaic power plant. Similarly the Swiss firm Etrion has committed to building an $8.8 \mathrm{MW}$ PV plant to supply power to the Aguas Blancas mine.

\section{B. Geothermal Energy}

The potential for geothermal energy in Chile is widely known. Some estimates put its potential at 16,000 MW. The government is expected to invest $\$ 200$ million into the sector within the next decade. The promise of geothermal energy in Chile has already attracted many multinational companies including ENEL, Geoglobal Energy, Energia Andina (founded by Antofogasta minerals), ENAP (state-owned), Magma Energy Chile, Hot Rock Limited. Interestingly, Energia Andina was founded by a mining company; this is precisely the kind of energetic-mining solutions the Chilean government should encourage.

However, as indicated by interviews with Chilean government officials, there is the burden of high risk with geothermal exploration and development. This is especially true with early-stage finance for geothermal energy which, in the event the exploration yields no positive results, leaves financiers with no investment return. This results in increased perceived risk in all future geothermal investments in Chile. The drilling of test wells is very expensive, and the risk of failure is very high. Yet the government does foresee great potential in geothermal investments. "From this perspective, and recognizing the great attraction of geothermal energy for our country due to its potential and high plant factor, we are preparing a new regulatory base to encourage investment based on this renewable resource" [29]. In addition, the government has created several laws to promote geothermal investments (Decree No. 142: Sources of Geothermal Energy; and Law No. 19,657: Geothermal Concessions). Still, similar to CSP and storage technology, the government should consider incorporating geothermal research into its knowledge capital.

\section{General Observations}

- The Chilean Mining industry (ranked first in the world for copper production, and fourth for conditions for mining investors), which makes up the majority of its GDP, will grind to a halt if the country's energy needs are not soon addressed.

- Where a majority of mining operations are, in the North of the country within and around the Atacama Desert, solar irradiation is nearly the highest on the planet.

- The mining industry uses many of the same technologies as geothermal energy. 
- Geothermal energy is also abundant in areas surrounding the main mines.

- Molten salt [30], a vital component of Concentrated Solar Power (CSP) which allows solar energy to be stored overnight, is abundant in the North of the country.

- Currently there are no Chilean CSP companies, and the government has not recognized this as a potential driver for innovation.

- Chile boasts one of the longest coastlines in the world, and therefore has a vast potential for offshore wind power.

- The government has done little to attract FDI into the offshore wind industry.

\section{Specific Policy Recommendations}

The Government should require the mining sector to source up to $20 \%$ NCRE by the year 2020 (increasing 1\% annually), matching European country commitments and adding to investor confidence.

- Targeted innovation research in Concentrated Solar Power for Universities.

- Research in molten salt energy storage technologies.

- Substantially ease geothermal exploration regulation. Promote exploration and innovation through mining company's expertise, capital, and know-how.

- Utilize international lenders for technology transfer and knowledge transfer.

\section{CONCLUSION}

The Chilean government has done very well to encourage FDI in the energy industry. Yet the uptake in large-scale renewable energy projects continues to move slowly, despite the country's promising geographical conditions for the incubation of renewable energy. Very specific national policies should focus on creating a Chilean technopole based on two RE technologies: Concentrated Solar Power and Molten Salt Storage. Since both technologies are bound together by virtue of their mutual dependence, the development of a technopole should be natural. The government can create policy to encourage the mining industry to work alongside this technopole so that all parties may enjoy the financial benefits of sustained energy through CSP in the future.

\section{REFERENCES}

[1] Government of Chile, 1982.
[2] "Clean Technology Fund: Investment Plan for Chile." Climate Investment Funds. CIF, n.d. Web. 1 Feb. 2013. pp. 5.

[3] ibid: 8 .

[4] "Chile: Barrier Removal for Rural Electrification with Renewable Energies." Renewable Energy Case Studies.

[5] Global Environmental Facility, Web. 26 Feb. 2013.. pp. 4.

[6] Chilean National Energy Commission, 2008.

[7] ibid: 25.

[8] ibid.

[9] ibid.

[10] "Clean Technology Fund: Investment Plan for Chile." Climate Investment Funds. CIF, n.d. Web. 1 Feb. 2013. pp. 8.

[11] ibid: 10 .

[12] Behnke, Rodrigo P., Dr., Guillermo J. Estévez, and Ignacio A. Arias. Las Energias Renovables No Convencionales En El Mercao Electrico Chileno. Santiago: Government of Chile, n.d. Print.

[13] pp. 121.

[14] ibid: 123.

[15] "Legal Framework." Ministry of Finance. Government of Chile, n.d. Web. 5 Feb. 2013.

[16] Pollitt, Michael G. "Electricity Reform in Chile : Lessons for Developing Countries." DSpace@MIT :. MIT Center for Energy and Environmental Policy Research, 2004. Web. 27 Jan. 2013.

[17] Dufey et al. "IISD: Opportunities and Domestic Barriers to Clean Energy Investment in Chile". 2010. pp. 15.

[18] ibid: 17.

[19] ibid: 33.

[20] ibid.

[21] Chile. Ministerio De Energia. Energy for the Future: National Energy Strategy 2012-2030. Gobierno De Chile, Feb. 2012. Web. 26 Dec. 2012.

[22] Interview: Pamela Moreno, National Energy Commission. June 17. 2012.

[23] Dufey et al. "IISD: Opportunities and Domestic Barriers to Clean Energy Investment in Chile". 2010. pp. 38.

[24] "Clean Technology Fund: Investment Plan for Chile." Climate Investment Funds. CIF, n.d. Web. 1 Feb. 2013. pp. 24.

[25] United States. UNEP and SEFI. Public Finance Mechanisms to Mobilise Investment in Climate Change Mitigation.

[26] By John Maclean, Jason Tan, Dennis Tirpak, Virginia Sonntag-O'Brien, and Eric Usher. UN, 2008. Web. 22 Jan. 2013.

$<$ http://sefi.unep.org/fileadmin/media/sefi/docs/UNEP_Public_Finance Report.pdf > pp. 24.

[27] ibid: 15

[28] Pollitt, Michael G. "Electricity Reform in Chile : Lessons for Developing Countries.” DSpace@MIT :. MIT Center for Energy and Environmental Policy Research, 2004. Web. 27 Jan. 2013. pp. 23.

[29] Interview: Pamela Moreno, National Energy Commission. June 17. 2012.

[30] Dufey et al. "IISD: Opportunities and Domestic Barriers to Clean Energy Investment in Chile". 2010. pp. 38. 